\title{
On Cultivating Learning Autonomy of English Major Students in China
}

\author{
Zhang Na \\ School of Foreign Languages and Cultures, Beijing Wuzi University, Beijing, China
}

\section{Email address:}

zhangna@bwu.edu.cn

\section{To cite this article:}

Zhang Na. On Cultivating Learning Autonomy of English Major Students in China. Education Journal. Vol. 9, No. 2, 2020 , pp. $43-47$.

doi: $10.11648 /$ j.edu. 20200902.12

Received: March 26, 2020; Accepted: April 16, 2020; Published: April 23, 2020

\begin{abstract}
Learning autonomy is a hot research topic in the field of foreign language education in recent years. It emphasizes that learners should learn to manage their own learning process in order to improve their autonomous learning ability. Even though scholars have different understandings about learner autonomy, they all agree that promoting learner autonomy is an important goal of foreign language education. For English major students in China, there is a great necessity to cultivate their learning autonomy due to the rapid development of information society, the goal of modern foreign language education, the particularity of language learning, and even the individual differences between language learners. However, the status quo of Chinese English major students' learning autonomy is worrying. They not only lack the awareness of learning autonomy, but also lack the abilities of interaction and cooperation. Furthermore, they have a poor use of language learning strategies and poor abstract thinking ability and self-control. Based on the necessity and status quo of English major students' learning autonomy in China, this paper puts forward many measures for cultivating English majors' autonomous learning abilities. From the perspective of school education system and environment, measures like giving English teachers greater autonomy in teaching, the reform of graded teaching for English majors, and establishing autonomous learning centers for English major students are recommended. From the perspective of teachers and classroom teaching, the measures include improvement of English teachers' awareness of learning autonomy, the change of English classroom teaching model, and guidance and training of systematic learning strategies. From the perspective of students and extracurricular learning, the following measures can be taken, which are strengthening of students' awareness of being independent, effective use of various learning resources and cooperative learning, and being a reflective learner.
\end{abstract}

Keywords: Learning Autonomy, English Major, Cultivation, China

\section{Introduction}

In the early 1980s, Holec first introduced the concept of "learning autonomy" into foreign language teaching. In the early and middle 1980s, Chinese scholars began to explore the field of autonomous learning. With the emergence of learners' subjectivity in learning, more and more experts and scholars begin to explore how to give full play to learners' subjectivity. Learning autonomy has become a hot topic in foreign language teaching and research in China. At present, the domestic research is mostly limited to the study of College English, and the research results for English majors are seldom focused on this. This paper aims to explore the theory and practice of cultivating English majors' learning autonomy in China.

\section{The Concept of Learning Autonomy}

Different scholars at home and abroad have different understandings of the concept of learning autonomy. At present, there is no unified definition. Holec holds that learning autonomy is the ability of learners to be responsible for their own learning. Autonomous learning is mainly manifested in five aspects: setting learning objectives, determining learning content and progress, choosing learning methods and skills, monitoring learning process and evaluating learning outcomes. [1] Zimmerman believes that as long as students are active participants in meta-cognition, motivation and behavior, their learning is autonomous. [2] Dam further points out that autonomous learning depends not only on individuals, but also 
on groups. [3] Only by cooperating with others can learners acquire autonomous learning ability well. Ryan \&. Deci (2000) discussed autonomous learning from the perspective of social psychology and sociolinguistics. He believed that autonomous learning was a process of learners' self-determination and self-regulation, which was not dominated by others, but could be interdependent with others, and could be promptly instructed by teachers and helped by peers. Domestic scholars made a comprehensive analysis of the definitions of learning autonomy and roughly divided them into the following four categories: competence theory, environment theory, responsibility theory and synthesis theory. "Competence theory" regards autonomy as a learner's self-management ability; "Environment theory" regards autonomy as requiring learners to be responsible for their own learning in any environment, while the environment plays a decisive role in promoting learner autonomy; "Responsibility theory" emphasizes that learners must be responsible for their own behavioral outcomes, and believes that in order to promote learner autonomy they must cultivate learners' responsibility. "Synthesis theory" defines learning autonomy from multiple levels. [4]

It is difficult to summarize the definition of "learner autonomy" in one sentence, and it is not scientific to simply judge the advantages and disadvantages of these terms, because scholars have expounded their concepts from different perspectives and levels. Although the definition of learner autonomy varies, there is at least a basic consensus among language scholars that promoting learner autonomy is an important goal of foreign language education.

\section{The Necessity of Cultivating English Major Students' Learning Autonomy}

\subsection{The Rapid Development of Information Society Requires English Majors to Develop Their Autonomous Learning Ability}

The rapid development of modern social science and technology increases the growth of the total amount of information. The frequency of updating information accelerates and the dynamics of knowledge make it impossible for people to meet the needs of society for occupation "once and for all" by relying on the knowledge and skills acquired in school education stage. The goal of lifelong education can only be achieved by cultivating students' learning autonomy. As the messenger of communication between language and culture, English majors shoulder the mission of information exchange. Only with the ability of autonomous learning, can education become a lifelong and continuous activity process, can the English major students meet the requirements of today's social development.

\subsection{The Goal of Modern Foreign Language Education Requires English Majors to Develop Their Autonomous Learning Ability}

The goal of modern foreign language education is to pay more and more attention to the cultivation of students' ability. [5] The syllabus for English majors in colleges and universities clearly points out that students should be trained to acquire knowledge, apply knowledge, analyze problems, and put forward opinions independently. The development of these abilities is not achieved overnight, nor can they be imparted directly by teachers. It requires students to practice independently and repeatedly under the guidance of teachers. Without autonomous learning ability and responsibility for one's own learning, one cannot practice and master the abilities required by one's major, nor can one achieve the goal of professional education.

\subsection{The Particularity of Language Learning Requires English Majors to Develop Their Autonomous Learning Ability}

The process of language learning is not only the process of learning language knowledge and skills, but also the process of understanding and mastering the social culture that language carries. A large number of studies have shown that learners' autonomous learning ability does promote language learning, especially second language learning. [6] To master a language skillfully, we should not only practice a lot of language skills such as listening, speaking, reading, writing and translating, but also understand all-embracing social culture in many ways and channels. Learning content and materials are not only limited to textbooks, but also rely on a large number of authentic materials in reality. Obviously, students can't accomplish these tasks in the limited class time. Only through autonomous learning, by choosing learning content according to their own situation, effectively planing, monitoring and evaluating their learning process, can they achieve the goal of effective learning.

\subsection{Individual Differences of Language Learners Require English Majors to Develop Their Autonomous Learning Ability}

Language learners' language acquisition ability is restricted by many factors, such as age, gender, motivation, attitude, cognitive style, cognitive strategies, etc. The influence of individual differences on language learning is obvious to all. Therefore, individualized teaching should be paid more attention to in language teaching, instead of one-size-fits-all teaching method. In view of the individual differences in language teaching, it is bound to provide students with more freedom of choice, such as allowing students to choose their own learning content, progress, methods and so on, which means that English majors must learn to learn autonomous learning.

\section{Analysis of the English Major Students' Status Quo of Learning Autonomy in China}

Although English major students in China are required to 
have the ability of autonomous learning from the perspectives of social development, educational objectives, language acquisition and language learners, the status quo is not optimistic. This is mainly manifested in the following aspects.

\subsection{English Majors' Awareness of Learning Autonomy Is Still Weak}

Influenced by traditional teaching methods, English major students in China are still accustomed to a spoon-feeding style of teaching. They passively complete teachers' assignments after class, and are unable to arrange their own learning content. They lack autonomy and initiative in learning, so they can not formulate their learning progress, let alone supervising and evaluating the learning process.

\subsection{Interactive and Cooperative Abilities of English Majors Need to Be Improved}

The ultimate goal of language learning is the cultivation of language communicative competence, which requires English majors to have good language expressing abilities and interactive and cooperative abilities. The process of language learning should also be realized in interactive and cooperative language practices. Chinese students are reserved and not good at speaking, which greatly affects the atmosphere of English classroom. To achieve autonomous learning in group interaction and cooperation, there is a long way to go and more efforts should be made from different perspectives.

\subsection{English Majors Have Poor Understanding and Poor Use of Language Learning Strategies}

Most English majors still pay more attention to learning content while ignoring learning methods. The mastery and training of learning strategies are excluded from the scope of learning, which greatly restricts the development of autonomous learning ability. They lack the initiative and the ability to apply learning strategies in their study.

\subsection{English Majors Have Poor Abstract Thinking Ability and Self-Control}

English majors are loaded with a heavy learning burden, and their learning materials are full of fragmented knowledge points, which makes them have little time to analyze the links of the knowledge points and reflect on their learning process. The understanding and remembering of numerous knowledge points require long-term accumulation and repetition. The learning methods that emphasizes memory rather than abstract thinking indirectly lead to the weak abstract thinking ability of English major students. In addition, endless language learning process requires persistent patience and perseverance, however, affected by the large number of girls in this major, their age, learning motivation and other factors, English majors normally have poor self-control. It would be a great test for English majors to take responsibility for their learning autonomy.

\section{Measures to Cultivate English Majors' Learning Autonomy}

Based on the above analysis on the concept of autonomous learning, the necessity of cultivating English major students' learning autonomy, the status quo of English major students' learning autonomy, combined with the characteristics of English major, measures can be taken to promote the cultivation of English major students' learning autonomy from multiple perspectives.

\subsection{Perspective of School Education System and Environment}

\subsubsection{Giving English Teachers Greater Autonomy in Teaching}

The classification of learning courses for English majors is more detailed. Basic language skills such as listening, speaking, reading, writing, translation and other related professional knowledge are trained separately. This is more targeted, and at the same time it also makes teachers pay more attention to a single aspect of language. If teachers are subjected to restrictions of teaching plans, contents and schedule, it is often difficult for them to break through the conventions. They dare not try abundant English learning materials and flexible teaching methods, and gradually they become more conventional. In addition, the characteristics of English curriculum make the learning materials of each unit relatively independent, and there will be more fresh learning materials coming out at any time. However, the setting of the teaching plan before the beginning of the courses makes it difficult for English teachers to adjust the teaching content and progress flexibly. Only by giving English teachers more autonomy in teaching can they give full play to their creativity and mobilize students' learning autonomy. [7]

\subsubsection{The Reform of Graded Teaching for English Majors}

Respecting students' individual differences and achieving individualized education is one of the goals of school education. Graded teaching is an effective way to realize individualized education. Nowadays, the reform of College English of non-majors is in full swing in China. Many colleges and universities have already realized graded teaching of college English, but most of the English majors follow a one-size-fits-all teaching model. Only by promoting the graded teaching of English majors can the students' individual development and the cultivation of their autonomous learning ability be enhanced.

\subsubsection{Establishing the Autonomous Learning Center for English Major Students}

Network technology provides learning tools and means for autonomous learning. Technology not only provides access to learning resources, but also provides more affordances for autonomous learning. [8]

At present, many colleges and universities in China have established Autonomous Learning Centers for College English of non-English majors, and have realized English 
teaching under the network environment. However, there are few English learning platforms or autonomous learning centers for English majors, which is far behind the construction of college English. In order to cultivate students' autonomous learning ability and provide learning platforms for students' autonomous learning, it is urgent to establish autonomous learning centers suitable for English majors, so as to provide the guarantee of learning equipment for realizing the educational objectives of English majors in colleges and universities.

\subsection{Perspective of Teachers and Classroom Teaching}

\subsubsection{Improvement of English Teachers' Awareness of Learning Autonomy}

Teachers' autonomy is the premise to realize students' autonomy. Students' autonomous learning ability is not innate, which requires that teachers should first urge students to re-examine their biased knowledge in autonomous learning, so as to realize the internal change of students' learning autonomy and the complete change of learning concept. If English teachers lack the idea of learning autonomy, it is very difficult for them to cultivate students' autonomous learning awareness in English teaching.

\subsubsection{The Change of English Classroom Teaching Model}

Under the concept of learning autonomy, the traditional teaching of knowledge will be transformed into the cultivation of student's ability. The main tasks of the teachers are to build students' autonomous learning environment and atmosphere, to supervise and check the students' learning process and to cultivate students' autonomous learning ability [9] To cultivate students' autonomous learning ability, we must thoroughly change the traditional teaching mode, truly take the learner as the center, and give full play to students' principal position. English teachers can use modern teaching methods such as heuristic teaching, task-based teaching and communicative teaching to highlight learner status, create a good cooperative learning environment for students, and cultivate their ability to think independently and learn cooperatively.

\subsubsection{Guidance and Training of Systematic Learning Strategies}

Learning strategies include cognitive strategies, meta-cognitive strategies and social/affective strategies. The ability to use learning strategies directly affects students' ability of autonomous learning. It is reasonable for some people to equate learner autonomy training with learning strategy training. [10] Only by training students to use various learning strategies reasonably can they be more responsible for their own learning and thus realize learners' autonomous learning.

\subsection{Perspective of Students and Extracurricular Learning}

\subsubsection{The Strengthening of Students' Awareness of Being Independent}

Passive learning autonomy is not real autonomy. Learners themselves should have the awareness of being independent, not completely relying on the guidance of teachers. The learners should take the initiative to exercise their ability to control their time reasonably, manage their emotions (including learning motivation, attitude, etc.) and independently reflect, analyze, make decisions and act on the various problems encountered in the learning process. [11]

\subsubsection{Effective Use of Various Learning Resources and Cooperative Learning}

With the development of learning autonomy research, the role of cooperation in cultivating autonomy has become a consensus. [12] With great amount of learning resources, students can have face-to-face discussions on the problems in independent learning. In addition, feedback and discussion among fellow students can promote mutual understanding and learning among them and enable teachers to further understand students' concerns or problems. [13]

Collaboration with others is not only an effective way to promote language learning, but also a necessary condition to cultivate autonomous learning ability. [14] Learners should be good at using modern scientific and technological means, cooperating with teachers and their peer learners, cultivating the ability to acquire knowledge independently and developing social communicative skills.

\subsubsection{Being a Reflective Learner}

Only when learners have a clear understanding of themselves, understand their own characteristics and learning styles, and constantly reflect on their own learning process, can they achieve effective autonomous learning in accordance with their own conditions. [15] To become a reflective learner, English majors can plan, implement, adjust and evaluate the whole process of autonomous learning consciously according to their own situation, and become effective learners with autonomous learning ability.

\section{Conclusion}

Learning autonomy is an important research topic in the field of foreign language learning. From the perspectives of social development, educational goals, language acquisition, and language learners, it is found that English majors are more in need of the ability to learn independently. However, in China, the status quo of autonomous learning among English majors is worrying, such as the weak awareness of independent learning, the lack of interaction and cooperation ability to be improved, the lack of learning strategies to restrict the development of independent learning ability, the poor ability of abstract thinking and self-control. In view of these barriers, measures can be taken from multiple perspectives to promote the cultivation of English majors' autonomous learning ability. Firstly, from the perspective of the school education system and educational environment, English teachers should be given more autonomy in teaching, the reform of graded teaching in English majors should be carried out, and an independent learning center for English 
majors should be established. Secondly, from the perspective of the teachers and classroom teaching, it is necessary to promote English teachers' awareness of autonomy, change the teaching mode in English classroom, and guide and train students' learning strategies. Thirdly, in terms of students and extracurricular learning, students should strengthen their sense of independence, cooperate with their peers to carry out cooperative learning, and timely reflect on the learning process.

\section{References}

[1] Holec, H. (1981). Autonomy in Foreign Language Learning. Oxford: Pergamon.

[2] Zimmerman, B. J. and Schunk, D. H. (eds) (1989). Self-regulated Learning and Academic Achievement: Theory, Research and Practice. New York, NY: Springer.

[3] Dam, L. (1995). Learner Autonomy 3: From Theory to Classroom Practice. Dublin: Authentik.

[4] Hua Weifen, (2009). On Foreign Language Learning Motivation and Learner Autonomy. Foreign Languages Research, 113 (1): 57-62.

[5] Wen Xuezhou, Mei Qiang \& Guan Yunsu. (2019). The Empirical Research on Factors Influencing Teaching Efficiency of Undergraduate Programs in Colleges and Universities. Journal of Higher Education Management, 13 (1): 104-112.

[6] Ron, P. (2016). Exploring Learner Autonomy: Language Learning Locus of Control in Multilinguals. International Journal of Multilingualism 2: 230-248.
[7] Young, J. T., Hafner, C. A. and Fisher, D. W. (2007). 'Shifting sands: Supporting teachers in facilitating independent learning'. In A. Barfield and S. Brown (eds) Reconstructing Autonomy in Language Education: Inquiry and Innovation. Basingstoke: Palgrave Macmillan, pp. 196-208.

[8] Reinders, H. \& C. White. Special issue commentary: Learner autonomy and new learning environments. Language Learning \& Technology, 2011 (3).

[9] Qiang Sheng. (2019). The Transformation of Teachers' roles in Course Teaching under the Background of Educational Modernization. China University Teaching, 11: 29-32.

[10] Holec, H. (1980) 'Learner training: Meeting needs in self-directed learning'. In H. B. Altman and C. V. James (eds) Foreign Language Learning: Meeting Individual Needs. Oxford: Pergamon, pp. 30-45.

[11] Ryan, R. M., \& Deci, E. L. (2000). Self-determination theory and the facilitation of intrinsic motivation, social development, and well-being. American Psychologist, 55: 68-78.

[12] Xu Jinfen. (2012). On critical cooperative autonomous learning in foreign language teaching. Foreign Language Education, 33 (3): 51-55.

[13] Murray, G. The social dimensions of learner autonomy and self-regulated learning. Studies in Self-Access Learning Journal, 2014 (4)

[14] Shaw, J. (2008). 'Team-teaching as negotiating autonomy and shared understandings of what we are doing'. In T. E. Lamb and H. Reinders (eds) Learner and Teacher Autonomy: Concepts, Realities and Responses. Amsterdam: John Benjamins, pp. 187-204.

[15] Vieira, F. (ed.) (2009). Struggling for Autonomy in Language Education: Reflecting, Acting, and Being. Frankfurt am Main: Peter Lang. 